\title{
Controlling airgap magnetic flux density harmonics in synchronous machines using field current injection
}

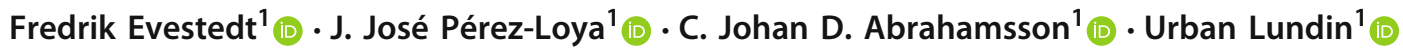

Received: 15 January 2020 / Accepted: 11 July 2020 / Published online: 29 July 2020

(c) The Author(s) 2020

\begin{abstract}
In this paper, a method to control the harmonic content of the magnetic flux density in the airgap of a synchronous machine is presented. Voltage harmonics in one phase as well as the exciting magnetic forces can be affected. Switched power electronics were used to provide the field current to a synchronous machine, the control added specific current harmonics to the DC field current in order to minimize either voltage harmonics or magnetic forces. The method is verified and compared with simulations and experiments on an existing electrical machine.
\end{abstract}

Keywords Synchronous machines · Electromagnetic forces · Voltage control · Field current control

\section{Introduction}

Magnetic flux density harmonics in the airgap of electric machines create distorted voltage waveforms and acts as exciting forces that can cause unwanted vibrations. These problems are difficult to mitigate when a machine is already in operation and therefore a lot of effort is made during the design phase to eliminate them. Still, many in-operation machines experience problems related to harmonics and often the solution is to mechanically reinforce and change modal shapes which is expensive and inconvenient. Vibrations and noise created by the magnetic flux in the mechanical parts are defined as magnetic. The magnetic forces have two origins, one is due to magnetostriction and the other is explained by Maxwell's stress tensor. It shows that the force exerted on a material is proportional to the magnetic flux density squared [1-4]. The magnetic flux density in the airgap of an electric machine can be described as

$$
B_{\delta}(\theta, t)=\Lambda(\theta, t) F(\theta, t)
$$

where $B_{\delta}$ is the airgap magnetic flux density, $\Lambda$ is the permeance per unit area and $F$ is the magnetomotive force [5]. From (1) and Maxwell's stress tensor, the forces acting on

Fredrik Evestedt

Fredrik.Evestedt@angstrom.uu.se

1 Division of Electricity, Department of Electrical Engineering, Uppsala University, Box 534, 75121 Uppsala, Sweden the structure of the electric machine can be found. The main parameters affecting the magnetic field in the airgap are listed by Traxler-Samek [6] among others.

Analytical and experimental work on reducing noise and vibration for grid connected as well as frequency converter connected induction machines by injecting proper current harmonics into the stator has been done previously [712]. A lot of research is currently being done on noise and vibration reduction in permanent magnet synchronous machines [13,14]. It has been shown that forces acting on the stator due to unbalanced magnetic pull can be compensated for by splitting the rotor winding and actively controlling the current to produce a resulting force vector $[15,16]$. Injection of current harmonics into the field winding of synchronous machines can be done to create an electromechanical filter, a machine that is connected in parallel to a non linear load and compensate for the harmonics produced by the load [17-19]. Reduction of harmonics in the phase voltage waveform of a single-phase synchronous machine by injection of current harmonics into the field winding has been shown in [20].

In this contribution a method to change the flux density harmonics in the airgap by injection of current harmonics in the field winding is presented. The focus is on affecting the phase voltage and the exciting magnetic forces. The appropriate currents are calculated through a minimization routine utilizing an in-house FEM model of an experimental generator. The results are then validated experimentally on a 12-pole synchronous machine in the lab. A simulation of a $33 \mathrm{MVA}$ full-scale generator with pronounced Walker noise [21] is 
done, to see what type of currents a full scale generator would require.

\section{Theory}

The idea is based on modulating the rotor field current with one or several AC components that targets specific magnetic flux density harmonics to either eliminate certain voltage harmonics or exciting force harmonics. The magnetic flux density in the airgap of an electric machine can be expressed as

$B_{s}(\theta, t)=\left[\sum_{n=1}^{\infty} A_{n} \sin \left[p\left(n \theta+\omega_{\mathrm{m}} t\right)\right]\right] B_{\mathrm{r}}(t)$,

where $A_{n}$ is a scaling factor for the different space harmonics, $\omega_{\mathrm{m}}$ is the mechanical angular frequency, $p$ is the number of pole pairs in the machine, and $B_{\mathrm{r}}$ is the amplitude of the radial magnetic flux density in the airgap produced by the rotor. The field current, $I_{\mathrm{f}}$, in the machine is changed by adding harmonics

$I_{\mathrm{f}}(t)=I_{\mathrm{f}, 0}+\sum_{k=1} \hat{I}_{\mathrm{f}, k} \sin \left(\omega_{k} t+\alpha_{k}\right)$,

where $\omega_{k}$ and $\alpha_{k}$ are the angular frequency and the phase of the added current harmonic. The contribution from the rotor to the magnetic flux density in the airgap depend on the field current according to

$B_{\mathrm{r}}(t)=B_{\mathrm{r}, 0}\left(I_{\mathrm{f}, 0}\right)+\sum_{k=1} \hat{B}_{\mathrm{r}, k}\left(I_{\mathrm{f}, k}\right) \sin \left(\omega_{k} t+\alpha_{k}\right)$.

By inserting (4) into (2) the complete expression for the magnetic field in the airgap of the machine when the rotor field current is modulated can be obtained as

$$
\begin{aligned}
B_{s}(\theta, t)= & {\left[\sum_{n=1}^{\infty} A_{n} \sin \left[p\left(n \theta+\omega_{\mathrm{m}} t\right)\right]\right]\left[B_{\mathrm{r}, 0}\left(I_{\mathrm{f}, 0}\right)\right.} \\
& \left.+\sum_{k=1} \hat{B}_{\mathrm{r}, k}\left(I_{\mathrm{f}, k}\right) \sin \left(\omega_{k} t+\alpha_{k}\right)\right] .
\end{aligned}
$$

In order to show the effect on stator output voltage (dependent on B directly) and exciting magnetic force (proportional to $B^{2}$ ), use $\omega_{k}=k p \omega_{\mathrm{m}}$, and consider adding one current harmonic $k$ to the DC-rotor current. Only the fundamental of the zeroth order field current, $A_{n}=1, n=1$ was considered for clarity. The magnetic flux density for this simplified case can then, from (5), be expressed as

$B_{S}(\theta, t)=B_{\mathrm{r}, 0}\left(I_{\mathrm{f}, 0}\right) \sin \left(p \omega_{\mathrm{m}} t\right)+\frac{B_{k}\left(\hat{I}_{\mathrm{f}, k}\right)}{2}(\cos [(k+1)$

$$
\begin{aligned}
& \left.p \omega_{\mathrm{m}} t-p \theta+\alpha_{k}\right]+\cos \left[(k-1) p \omega_{\mathrm{m}} t+p \theta\right. \\
& \left.\left.+\alpha_{k}\right]\right)
\end{aligned}
$$

The stator output voltage of the machine can be obtained by integrating $\theta$ for one coil span and the number of poles. This means that a " $k+1$ ", or " $k-1$ ", component added in the field current will affect the voltage component " $k$ ". The method can easily be generalized to include higher harmonics.

Equation (6) was squared to get an expression that is directly proportional to the exciting force, since the Maxwell stress tensor depends partly on the square of the flux density. One point per pole on the stator side was of interest, $\theta=0^{\circ}$ was chosen for simplicity. The amplitude and order of the $B^{2}$ harmonics can be extracted from

$$
\begin{aligned}
B_{s}^{2}(t)= & {\left[B_{\mathrm{r}, 0}\left(I_{\mathrm{f}, 0}\right) \cos \left(p \omega_{\mathrm{m}} t\right)+\frac{B_{k}\left(\hat{I}_{\mathrm{f}, k}\right)}{2}(\cos [(k+1)\right.} \\
& \left.\left.\left.\left.\left.p \omega_{\mathrm{m}} t\right)\right]+\cos \left[(k-1) p \omega_{\mathrm{m}} t\right)\right]\right)\right]^{2} \\
= & \frac{B_{0}^{2}\left(I_{\mathrm{f}, 0}\right)}{2}\left[1+\cos \left(2 p \omega_{\mathrm{m}} t\right)\right]+\frac{B_{k}\left(I_{\mathrm{f}, k}\right) B_{0}\left(I_{\mathrm{f}, 0}\right)}{2} \\
& {\left[\cos \left[(k+2) p \omega_{\mathrm{m}} t\right]+\cos \left[(k-2) p \omega_{\mathrm{m}} t\right]+2 \cos \right.} \\
& {\left.\left[k p \omega_{\mathrm{m}} t\right]\right]+\frac{B_{k}^{2}\left(I_{\mathrm{f}, k}\right)}{8}\left[2+\cos \left[2(k+1) p \omega_{\mathrm{m}} t\right]\right.} \\
& +\cos \left[2(k-1) p \omega_{\mathrm{m}} t\right]+2 \cos \left(2 k p \omega_{\mathrm{m}} t\right) \\
& \left.+2 \cos \left(2 p \omega_{\mathrm{m}} t\right)\right]
\end{aligned}
$$

where $\alpha_{k}$ is set to $0^{\circ}$. The expression (7) contains only harmonic waves of double order (e.g. for a $50 \mathrm{~Hz}$ system the fundamental is $100 \mathrm{~Hz}$ ). To affect a harmonic of order $k$, whose amplitude is $B_{k}\left(I_{\mathrm{f}, k}\right) B_{0}\left(I_{\mathrm{f}, 0}\right)$, a current harmonic of the same order, $k$, should be added, and the phase adjusted accordingly. However, there is a drawback as adding a $k$-th component will also affect the amplitude of harmonics $k \pm 2$.

\section{Method}

The method was first tested and verified in a finite element code and then comparative experiments were carried out on a smaller synchronous machine in the lab. A simulation was then made of a 33 MVA generator with known vibration problems, the specifications for each machine is shown in Table 1. The machine in the lab had a solid rotor rim where eddy currents develop if an AC-component is added to the field current, this limited the airgap magnetic flux density at higher frequencies. 
Table 1 Machine data for the experimental generator and a full-scale generator with noise problems

\begin{tabular}{lll}
\hline Parameter & Experimental generator & Full-scale generator \\
\hline Rated Power & $200 \mathrm{kVA}$ & $33 \mathrm{MVA}$ \\
Rated field current & $12.48 \mathrm{~A}$ & $480 \mathrm{~A}$ \\
Frequency & $50 \mathrm{~Hz}$ & $50 \mathrm{~Hz}$ \\
Field winding turns & 162 & 21 \\
Field winding resistance & $3 \Omega$ & $0.288 \Omega$ \\
Field winding inductance & $1.95 \mathrm{H}$ & $1.11 \mathrm{H}$ \\
Number of poles & 12 & 76 \\
Stator slots & 108 & 504 \\
Airgap length & $8.3 \mathrm{~mm}$ & $12 \mathrm{~mm}$ \\
Stator inner diameter & $725 \mathrm{~mm}$ & $9000 \mathrm{~mm}$ \\
Stator length & $303 \mathrm{~mm}$ & $820 \mathrm{~mm}$ \\
\hline
\end{tabular}

Measurements were made at no-load operation at a lower speed in order to demonstrate the method. The frequency response from the applied field current to airgap magnetic flux was done to characterize the machine's response to the injected field current. Another aspect of the added harmonics is worth to note. Since adding the harmonic affects the flux density, it will automatically affect everything that depends on the flux density. So if a minimization with regard to a special harmonic is done side-bands will develop, see (6) (7), that can increase instead. It is possible to add additional harmonics to reduce the effect of the developed side bands. As an example, assume that we want to affect the 5 th harmonic in the phase voltage by adding a 4th and 6th harmonic in the field current. The 4th harmonic will affect the $3 \mathrm{rd}$ and the 5 th harmonic in the phase voltage and the 4th harmonic in $B^{2}$. The 6 th harmonic will affect the 5 th and the 7 th harmonic in the phase voltage and the 6th harmonic in $B^{2}$.

\subsection{Finite element simulation}

The method was implemented in an in-house finite element code. The code is adapted for synchronous machines and have been extensively verified against different machines, and operating conditions. The experimental and the fullscale generator were modelled using 5776 and 107,170 mesh nodes respectively, see Fig. 1. The time step was commensurate with the mesh in order to avoid numerical noise, and were $6.945 \times 10^{-5} \mathrm{~s}$, and $6.287 \times 10^{-5} \mathrm{~s}$ for the two machines, respectively. For the experimental generator only one pole was modelled due to the integer slots per pole per phase compared to the full-scale generator where a large part of the geometry needed to be modelled due to fractional slots per pole per phase. Second order basis functions were used in order to better resolve higher order harmonics.

In order to find amplitudes and phase angles of the added harmonics a minimization procedure was used. The procedure sets the amplitude and phase of each added harmonic

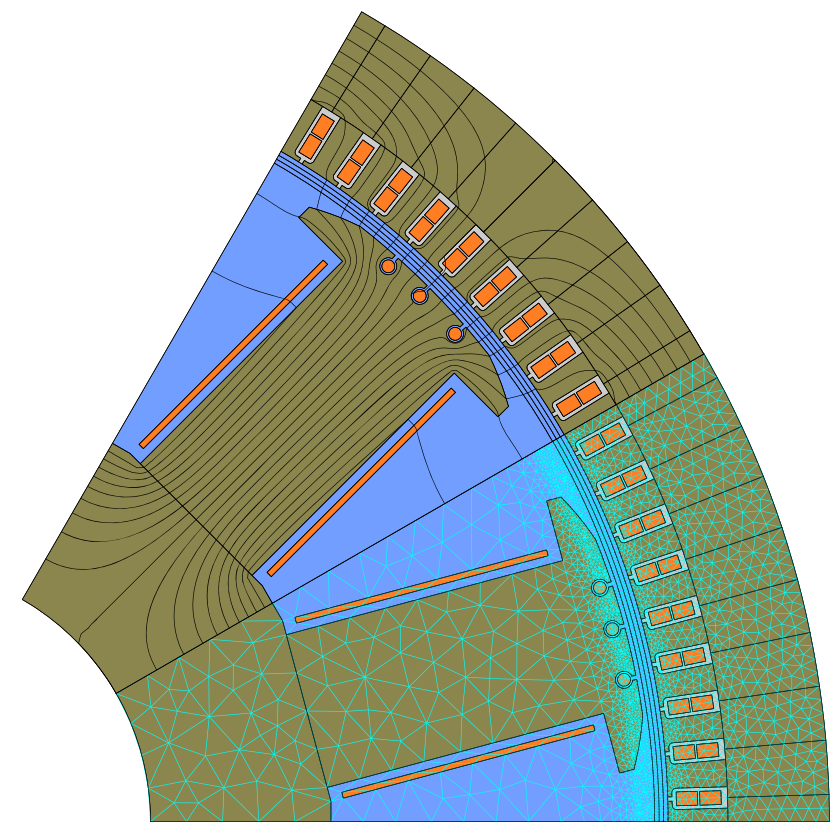

Fig. 1 Simulated geometry with flux lines and mesh for the 200kVA experimental generator

in the field current, then a time stepped simulation was performed. Thereafter the quantity that should be minimized was Fourier transformed and the harmonics were extracted. The minimization returned with updated values for the amplitude and phase angle and the procedure iterated until the desired harmonic component was below the minimization target. The minimization procedure used a Newton method and calculated the Jacobian numerically and made step-wise improvements based on the direction of the minima. Several numerical implementations and standard Fortran implementations were tested, and they all converged to the same result and eventually the most effective one was used. 


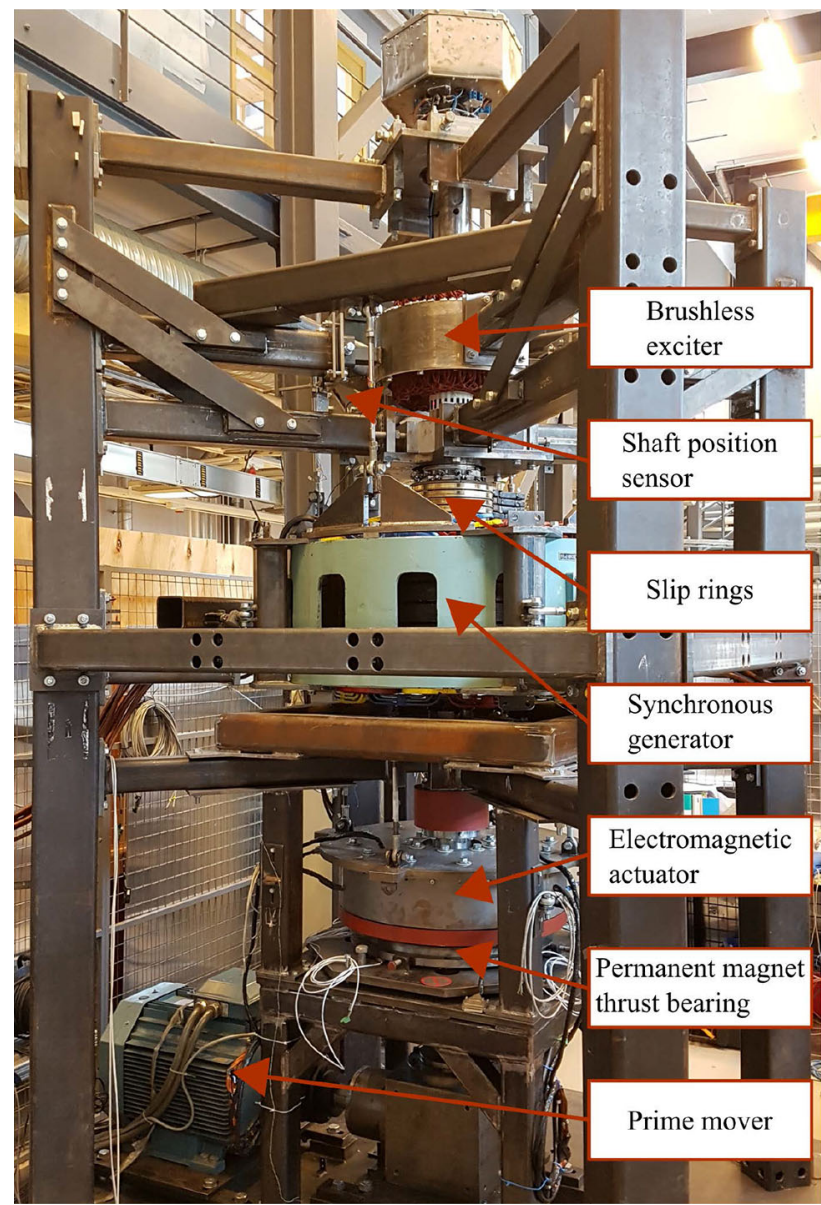

Fig. 2 Experimental test rig used for the experiments

\subsection{Experimental setup}

A test-rig, shown in Fig. 2, with a frequency converter controlled induction machine as the prime mover of the shaft was used. The test-rig had a 12 pole synchronous generator mounted on the shaft, and the pole shoes were laminated and the rotor rim was solid [22]. The machine was constructed to have a large airgap between stator and rotor resulting in low nominal airgap flux density compared to conventional machines. The airgap magnetic flux was measured by an in-house designed flux density sensor mounted on a stator tooth [23]. The angular position of the shaft is required to be able to generate the appropriate current waveform, for this purpose an optical sensor was used that produced a pulse once every revolution. The angular position was approximated from this pulse and the rotational speed of the machine.

The field winding of the test generator was connected through slip rings to two power electronic legs on a Powerex PP200T120-ND IGBT stack with DC-link voltage $V_{\mathrm{DC}}=$ $60 \mathrm{~V}$ and switching frequency $f_{s}=10 \mathrm{kHz}$. The shaft angular position sensor and current measurement was used

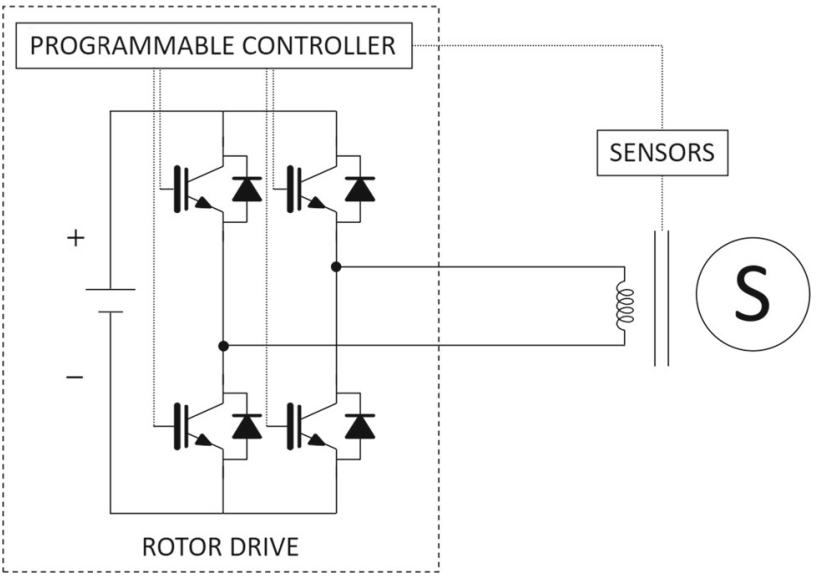

Fig. 3 Simplified block diagram showing the field winding excitation circuit. The connection between the $\mathrm{H}$-bridge and the field winding is done through slip rings

as input to a National Instruments sbRIO-9606 based field current controller. It controlled the field current utilizing a fixed frequency bang-bang control scheme; the polarity of the field winding voltage was set each iteration depending on if the measured current was above or below a set reference. The set-point value was based on the shaft angular position measurement and the targeted harmonics. Current was measured with a LEM LA55-p hall effect based current sensor sampled at $40 \mathrm{kHz}$ with a negligible amount of noise. In Fig. 3 a simplified block diagram of the system setup is shown.

\subsection{Full-scale generator, 33 MVA, with noise problems due to electromagnetic Walker harmonics}

The method was tested by simulating a full-scale generator that emitted audible noise at $f_{w}=700 \mathrm{~Hz}$, it had been confirmed that the noise was due to Walker noise [24] that excited a mechanical resonance. The Walker noise arises due to interaction of permeance harmonics and rotor mmf. The Walker noise frequency is

$f_{w}=2 f_{\text {el }} \operatorname{nint}(\mathrm{qm})$,

where $f_{e l}$ is the stator electric frequency of the machine, $q$ the number of slots per pole and phase, $m$ the number of phases in the machine, and nint () denotes the nearest integer. By injecting a 14th order field current harmonic the noise can potentially be eliminated by reducing the exciting force at the resonance frequency. 


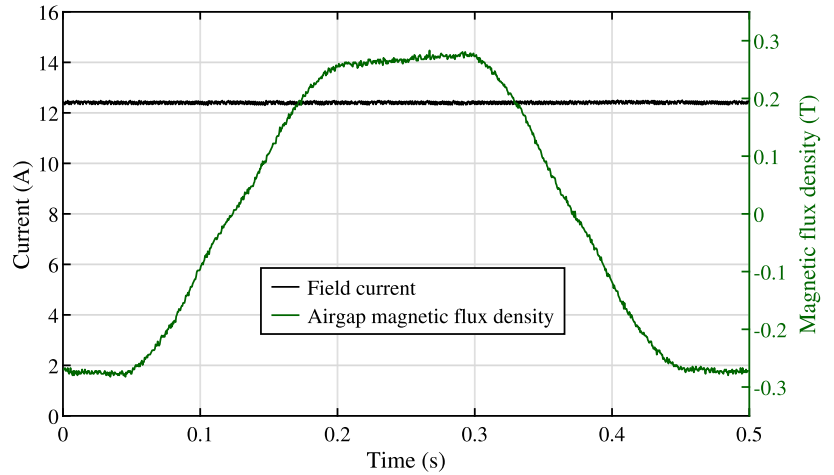

Fig. 4 Measured current and magnetic flux density waveforms in the $200 \mathrm{kVA}$ generator for one period measured at one point in the airgap with constant $I_{\mathrm{f}}=12.48 \mathrm{~A}$, with $w_{\mathrm{m}}=2 \pi f_{\mathrm{m}}=2 \pi \frac{1}{3}$

\section{Results}

\subsection{Airgap magnetic flux density waveform at constant field current}

In Fig. 4 one period of the airgap magnetic flux density at a point with rated constant field current is shown. It is used as reference to compare both simulation and experimental results. It is seen that the current ripple is quite small. This is due to the large time constant of the field winding.

\subsection{Magnitude and phase response from applied field current to magnetic flux density}

The FEM simulations were done in 2D and do not take into account the 3D effects that occur, e.g. eddy currents. To get those characteristics a magnitude and phase response from applied field current $\left(I_{\mathrm{f}}\right)$ to magnetic flux density $(B)$ on one point at the stator was done, see Fig. 5. A considerable reduction in measured magnetic flux density is observed as the frequency of the applied field current is increased. This can largely be attributed to the solid rotor rim where eddy currents develop.

\subsection{Harmonic minimization in the 200 kVA experimental generator}

In Table 2 the parameters for the added field current harmonics as described in (3) is listed, for all cases $I_{\mathrm{f}, D C}=12.48 \mathrm{~A}$. The harmonic field current amplitudes injected in the experiments were higher than the ones from the minimization to compensate for the eddy current effects in the solid rotor rim.

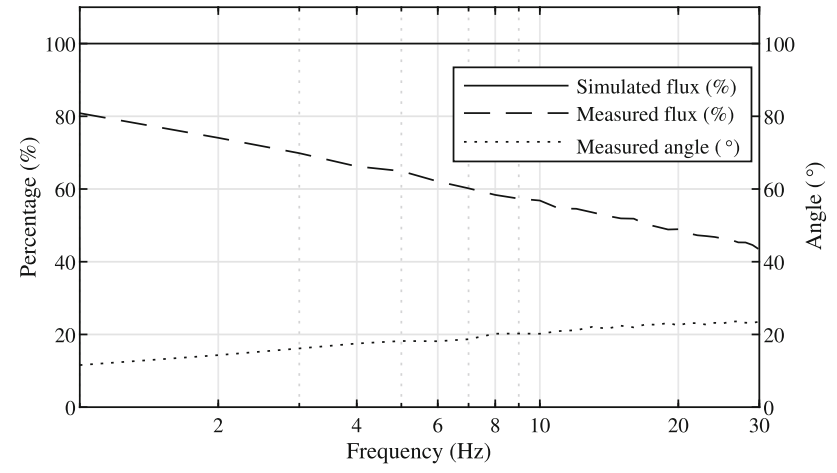

Fig. 5 Magnitude and phase response in the 200kVA generator from applied field current $\left(I_{\mathrm{f}}\right)$ to magnetic flux density $(B)$. The data is normalized with the simulated flux density for easy comparison

\subsubsection{Minimization of harmonics in the output phase voltage}

Minimization of the 3 rd harmonic in one of the phase voltages is done by adding 2nd and 4th order harmonics to the applied field current. See Fig. 6 for the actual measured waveforms over one period of magnetic flux density.

The magnitude of the harmonics in output phase voltage and the magnetic flux density squared at one point on a stator tooth is presented in Fig. 7. The values are normalized to the fundamental component of each quantity. Minimizing the 3rd harmonic in one phase voltage will also affect the surrounding harmonics, the sidebands. Thus, it will also affect the exciting forces. Experimental verification was done for elimination of the 3rd voltage harmonic, but in principle an arbitrary amount of harmonics can be minimized. The minimization of harmonic 3 and 5 was also simulated, the result is shown in Fig. 8. Adding a relatively high 6th order harmonic affect the 7th harmonic in the phase voltage. Due to the minimization in one phase voltage the other two phase voltages will be affected.

In Fig. 9 the stator voltages as a function of time obtained from simulations and experiments before and after minimization of the 3rd harmonic in $U_{a}$ are shown. In Fig. 10 the Fourier transform of the measured voltages in the experiment is presented. An increase in the other two phase voltages is observed. In Table 3 the total harmonic distortion of the phase voltages for constant field current compared to minimization of 3rd harmonic in $U_{a}$ is presented.

\subsubsection{Minimization of harmonics in $B^{2}$}

Minimization of the 4th harmonic in the magnetic flux density squared is done by adding a 4th order harmonic to the applied field current. See Fig. 11 for the actual measured waveforms over one period of magnetic flux density. The magnitude of the harmonics in output phase voltage and the 
Table 2 Amplitude and phase of the injected field current for different minimization targets applied to the experimental generator

\begin{tabular}{|c|c|c|c|c|c|}
\hline \multirow{2}{*}{$\begin{array}{l}\text { Target harmonic } \\
\text { Voltage }\end{array}$} & \multirow{2}{*}{$\begin{array}{l}\text { Injected current } \\
\text { Harmonic }(\mathrm{k})\end{array}$} & \multicolumn{2}{|l|}{ Simulation } & \multicolumn{2}{|l|}{ Experiment } \\
\hline & & Amplitude (A) & Phase (rad) & Amplitude (A) & Phase (rad) \\
\hline \multirow[t]{2}{*}{3} & 2 & 0.186 & 1.157 & 0.279 & 1.157 \\
\hline & 4 & 0.220 & 2.116 & 0.330 & 2.116 \\
\hline \multirow[t]{3}{*}{3 and 5} & 2 & 0.353 & 2.272 & & \\
\hline & 4 & 0.039 & 0.435 & & \\
\hline & 8 & 0.135 & 2.911 & & \\
\hline$B^{2}$ & Harmonic (k) & Amplitude (A) & Phase (rad) & Amplitude (A) & Phase (rad) \\
\hline 4 & 4 & 1.562 & 5.702 & 2.343 & 5.702 \\
\hline \multirow[t]{2}{*}{4 and 8} & 4 & 1.550 & 5.703 & & \\
\hline & 8 & 0.185 & 1.914 & & \\
\hline
\end{tabular}

The minimization target is defined in the left column of the table

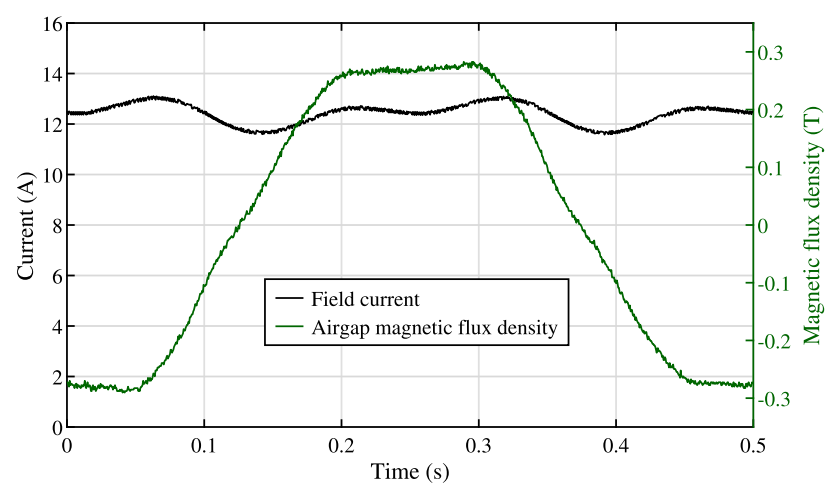

Fig. 6 Measured current and magnetic flux density waveforms in the $200 \mathrm{kVA}$ generator for one period measured at one point in the airgap with $I_{\mathrm{f}}$ modulated to eliminate the $3 \mathrm{rd}$ harmonic in the phase voltage, with $w_{\mathrm{m}}=2 \pi \frac{1}{3}$

magnetic flux density squared at one point on a stator tooth is presented in Fig. 12. The values are normalized to the fundamental component of each quantity. Experimental verification was done for elimination of the 4th harmonic but, as mentioned previously, in principle an arbitrary amount of harmonics can be minimized. In Fig. 13 the simulated result for minimization of both 4th and 8th harmonic of the magnetic flux density squared is shown. It can be observed that adding additional harmonics in $B^{2}$ reduces the overall harmonic content of the exciting forces.

\subsubsection{Minimization of electromagnetic walker harmonics in the 33 MVA full-scale generator}

The minimization routine was done in FEM for the electric machine and the resulting field current is presented in Table 4, where it can be seen that a harmonic of $4.2 \%$ of the DCcomponent has to be added to remove the desired exciting force. In Fig. 14 the results of the minimization is shown, the 14 th harmonic in $B^{2}$ is eliminated.
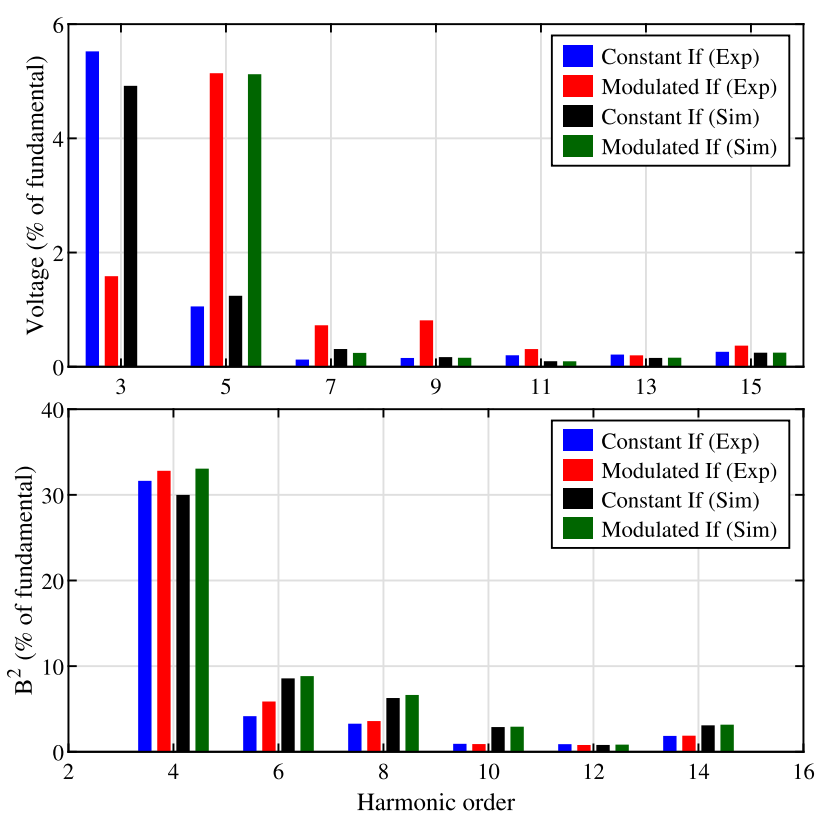

Fig. 7 Magnitude of harmonics at constant and modulated field current in the 200kVA generator from simulation and experiment, the 3rd harmonic in the phase voltage is minimized. Top part: Output phase voltage. Bottom part: $B^{2}$ at one point on the stator. Harmonic order 1 equals $2 \mathrm{~Hz}$

\section{Discussion}

The time constant of the field winding, available DC-voltage for the rotor inverter, and possible eddy currents on the magnetic circuit limits the maximum field current amplitudes and frequencies that can be modulated.

The voltage needed to modulate the 4th harmonic field current, $\hat{I}_{\mathrm{f}, 4 t h}=1.262 \mathrm{~A}$, in the experimental test generator at nominal speed is 


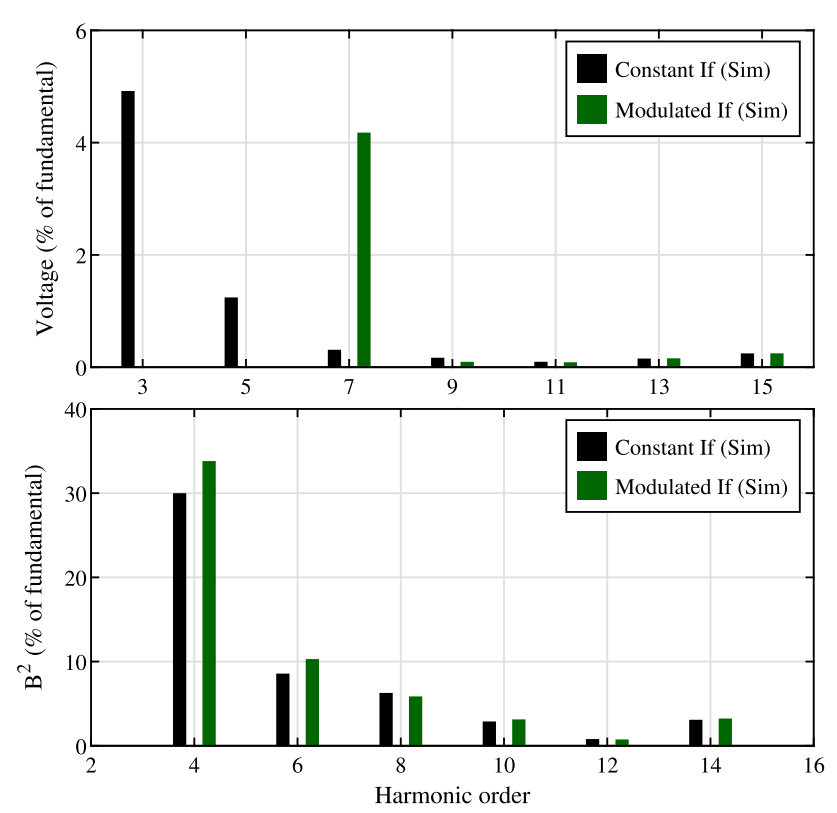

Fig. 8 Magnitude of harmonics at constant and modulated field current in the $200 \mathrm{kVA}$ generator from simulation, the $3 \mathrm{rd}$ and 5 th harmonic in the phase voltage is minimized. Top part: Output phase voltage. Bottom part: $B^{2}$ at one point on the stator
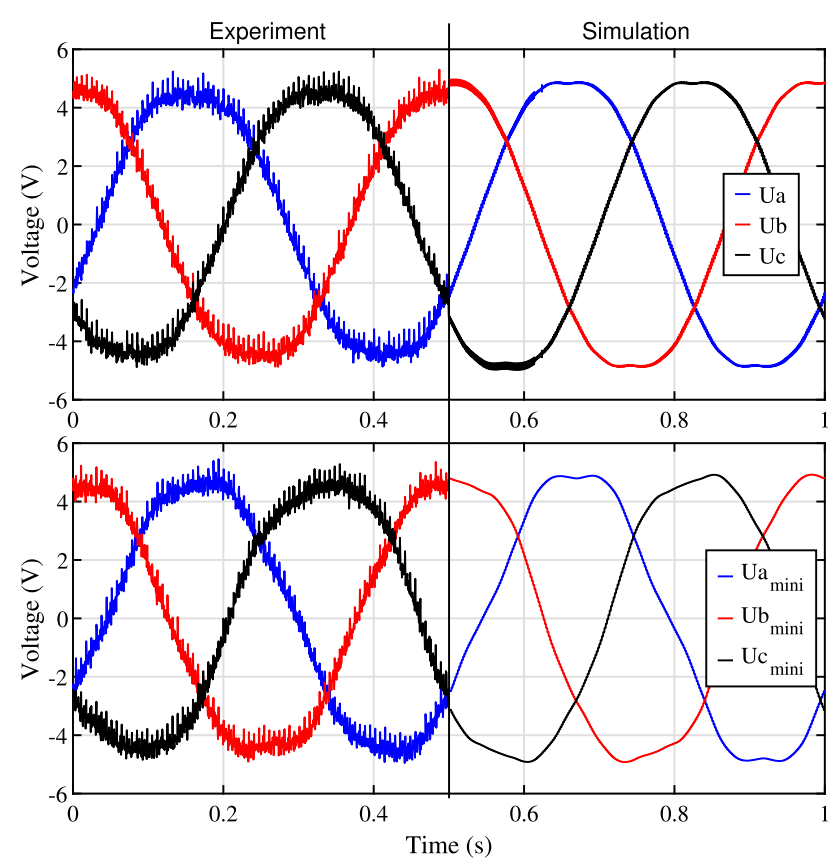

Fig. 9 Stator output phase voltages from experiments and simulation. Top part: Phase voltages with constant $I_{\mathrm{f}}=12.48 \mathrm{~A}$. Bottom part: Phase voltages with minimization of $3 \mathrm{rd}$ harmonic in $U_{a}$. The high frequency noise on the waveforms from the experiments is measurement noise

$$
\begin{aligned}
U_{\mathrm{f}, 4 \mathrm{th}} & =L \frac{d I_{\mathrm{f}, 4 \mathrm{th}}}{d t}=-L \hat{I}_{\mathrm{f}, 4 \mathrm{th}} 4 p \omega_{\mathrm{m}} \sin \left(4 p \omega_{\mathrm{m}} t+\alpha_{4}\right) \\
& =-3847 \sin \left(4 p \omega_{\mathrm{m}} t+\alpha_{4}\right),
\end{aligned}
$$

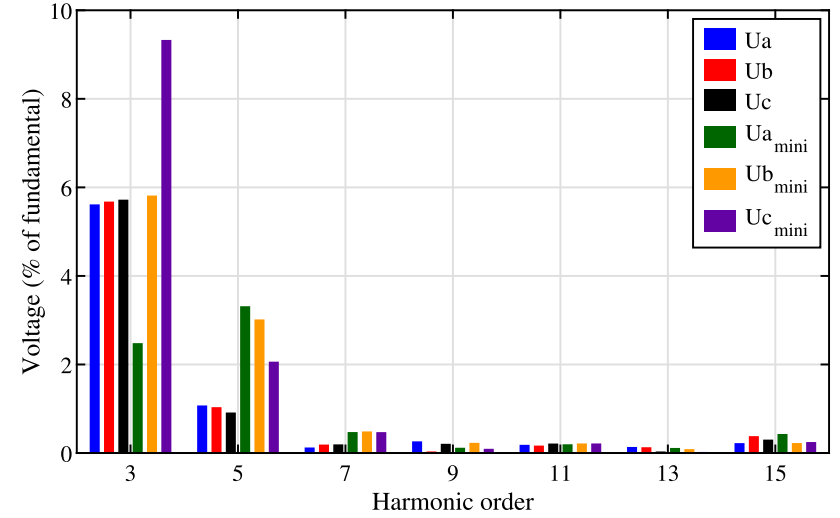

Fig. 10 Magnitude of harmonics in the measured phase voltages in the $200 \mathrm{kVA}$ generator with constant $I_{\mathrm{f}}=12.48 \mathrm{~A}$, with minimization of 3rd harmonic in $U_{a}$

Table 3 Left: THD of phase voltage with constant field current. Right: THD of phase voltage with minimization of $3 \mathrm{rd}$ harmonic in $U_{a}$ is presented

\begin{tabular}{llll}
\hline Phase & THD $(\%)$ & Phase & THD $(\%)$ \\
\hline$U a$ & 5.73 & $U a_{\text {mini }}$ & 4.20 \\
$U b$ & 5.79 & $U b_{\text {mini }}$ & 6.58 \\
$U c$ & 5.81 & $U c_{\text {mini }}$ & 9.57 \\
\hline
\end{tabular}

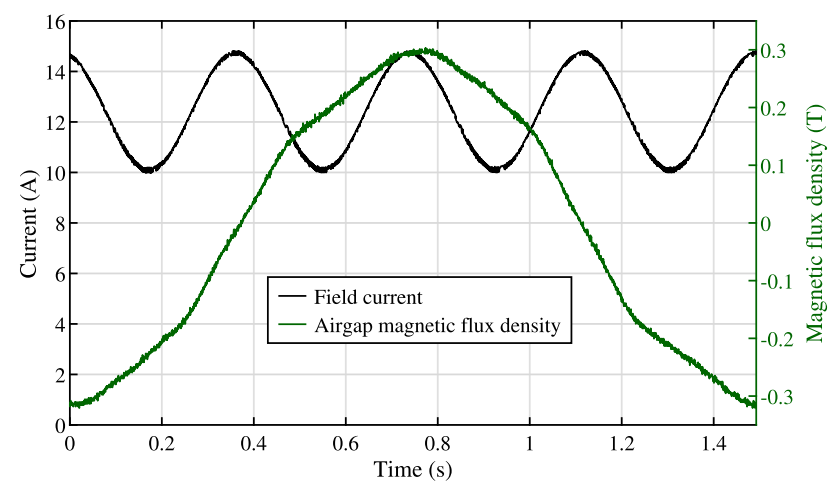

Fig. 11 Measured current and magnetic flux density waveforms in the $200 \mathrm{kVA}$ generator for one period measured at one point in the airgap with $I_{\mathrm{f}}$ modulated to eliminate the 4th harmonic in magnetic flux density squared, with $w_{\mathrm{m}}=2 \pi \frac{1}{9}$

which has a maximal value of $3847 \mathrm{~V}$. For comparison the nominal field voltage is $U_{\mathrm{f}}=36.8 \mathrm{~V}$. Worth noting is the unusually high field winding inductance in the test generator $L_{\mathrm{f}}=1.95 \mathrm{H}$, due to the large number of turns in the field winding. This estimate does not include the eddy current effect which also limits the bandwidth. For the method to be feasible the need for such high field voltage must be reduced. The eddy currents were not included in the FEM model but makes a big impact on the resulting magnetic flux density from a change in field current. To remedy these problems the following modifications can be done to the electric machine. 

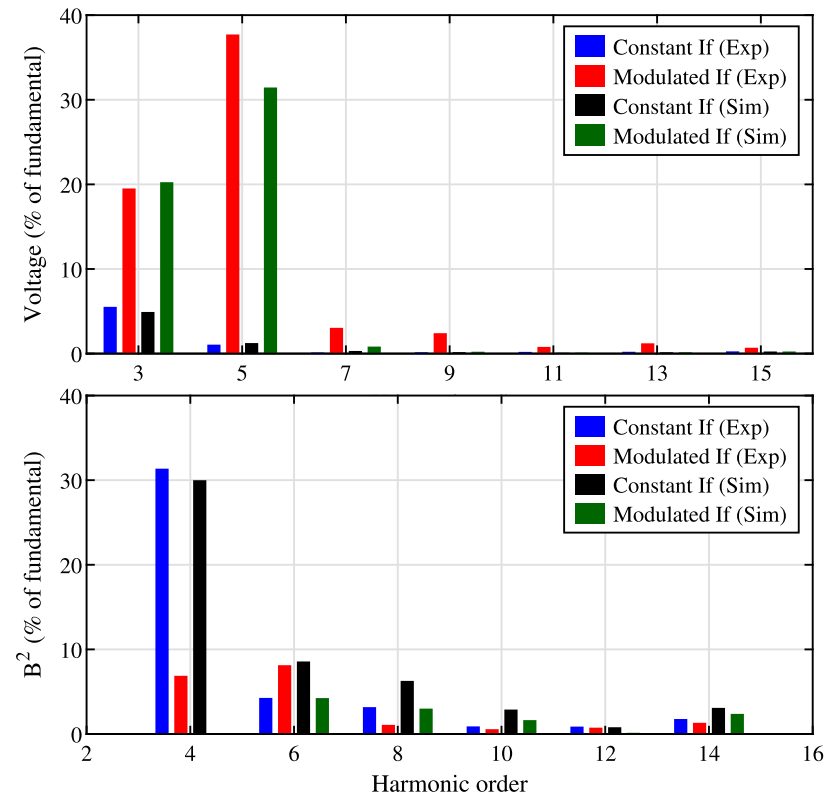

Fig. 12 Magnitude of harmonics at constant and modulated field current in the $200 \mathrm{kVA}$ generator from simulation and experiment, the 4th harmonic in the magnetic flux density squared is minimized. Top part: Output phase voltage. Bottom part: $B^{2}$ at one point on the stator. Harmonic order 1 equals $\frac{2}{3} \mathrm{~Hz}$

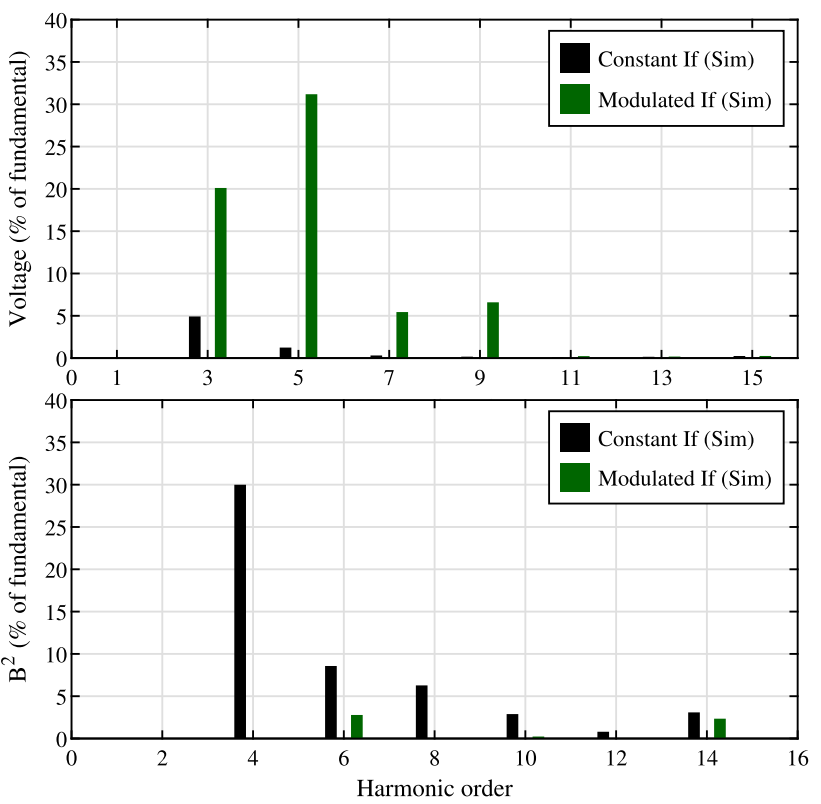

Fig. 13 Magnitude of harmonics at constant and modulated field current in the $200 \mathrm{kVA}$ generator from simulation, the 4th and 8th harmonic in the magnetic flux density squared is minimized. Top part: Output phase voltage. Bottom part: $B^{2}$ at one point on the stator

- Increase the field winding supply voltage.

- Split the field winding into parallel circuits to increase the supply voltage for each pole.

- Laminate the complete rotor.
Table 4 Amplitude and phase of the injected field current for the 33 MVA full-scale generator

\begin{tabular}{llll}
\hline$B^{2}$ harmonic & $\begin{array}{l}\text { Injected current } \\
\text { Harmonic }(\mathrm{k})\end{array}$ & Simulation & \\
\cline { 3 - 4 } & Amplitude (A) & Phase (rad) \\
\hline 14 & 0 & 480 & - \\
& 14 & 20.517 & 1.949
\end{tabular}

The minimization target is defined in the left column of the table
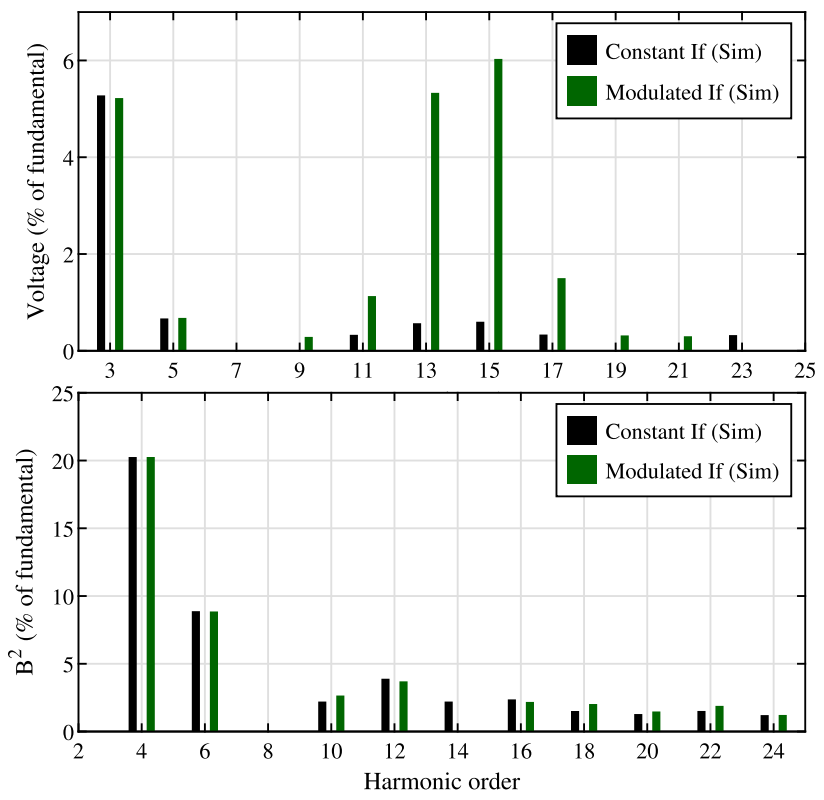

Fig. 14 Magnitude of harmonics at constant and modulated field current from simulation of the 33 MVA generator, the 14th harmonic in the magnetic flux density squared is minimized. Top part: Output phase voltage. Bottom part: $B^{2}$ at one point on the stator

A natural question arises as to the applicability of the suggested method. The need for a very high rate of change in the field current makes it very hard to implement in a normal synchronous machines at rated frequency. The minimization of the exciting force is done on one point per pole. This means that for adjacent tangential positions the exciting force will not be minimized. However, normally the mechanical vibrations form standing waves of different modal shapes on the stator which means that if the force minimization is done in a position where the amplitude peaks (not the standing wave nodes) the method can still be useful to reduce vibration amplitudes. When minimizing for vibration it is important to find a good balance between the amplitude reduction in flux density versus the additional voltage harmonics induced in the stator windings. The voltage harmonic method can be useful for single phase synchronous machines. It is also possible to increase a chosen harmonic using a similar approach to what has been presented here, maybe for so called energy harvesting. The FEM models and minimization shows good correspondence with the experiments. Injection of alternat- 
ing current in the field winding create additional losses in damper bars and the rotor iron but the effect is small, at the levels used here.

\section{Conclusion}

In this paper a method to minimize a specific harmonic in one output phase voltage or magnetic flux density harmonic is shown. It was done by injecting harmonics into the field current to change the airgap magnetic flux density. The method has been demonstrated during no-load operation but would work equally well during loaded operation.

Acknowledgements Open access funding provided by Uppsala University. The authors would like to thank Dr. Arne Wolfbrandt for his help in developing the finite-element code. The research presented was carried out as a part of "Swedish Hydropower Centre - SVC". SVC has been established by the Swedish Energy Agency, Elforsk and Svenska Kraftnät together with Luleå University of Technology, The Royal Institute of Technology, Chalmers University of Technology and Uppsala University. www.svc.nu.

Open Access This article is licensed under a Creative Commons Attribution 4.0 International License, which permits use, sharing, adaptation, distribution and reproduction in any medium or format, as long as you give appropriate credit to the original author(s) and the source, provide a link to the Creative Commons licence, and indicate if changes were made. The images or other third party material in this article are included in the article's Creative Commons licence, unless indicated otherwise in a credit line to the material. If material is not included in the article's Creative Commons licence and your intended use is not permitted by statutory regulation or exceeds the permitted use, you will need to obtain permission directly from the copyright holder. To view a copy of this licence, visit http://creativecomm ons.org/licenses/by/4.0/.

\section{References}

1. Shahaj A (2010) Mitigation of vibration in large electrical machines: Ph.D. dissertation, University of Nottingham

2. Vijayraghavan P, Krishnan R (1999) Noise in electric machines: a review. IEEE Trans Ind Appl 35(5):1007-1013

3. Gieras JF, Wang C, Lai JC (2006) Noise of polyphase electric motors. Taylor \& Francis Group, Abingdon

4. Maliti KC (2000) Modelling and Analysis of Magnetic Noise in Squirrel-Cage Induction Motors: Ph.D. dissertation, Royal Institute of Technology

5. Ranlöf M, Perers R, Lundin U (2010) On permeance modeling of large hydrogenerators with application to voltage harmonics prediction. IEEE Trans Energy Convers 25(4):1179-1186

6. Traxler-samek G, Lugand T, Uemori M (2012) Vibrational forces in salient pole synchronous machines considering tooth ripple effects. IEEE Trans Ind Electron 59(5):2258-2266

7. Bauw G, Balavoine F, Cassoret B, Ninet O, Romary R (2017) Damper winding for noise and vibration reduction of PWM-fed induction machines. In: IEEE international electric machines and drives conference. IEMDC 2017

8. He S., Huang J, Kang M (2017) A novel third harmonic current injection method to optimize the air-gap flux for multiphase induc- tion machine. In: 2017 20th international conference on electrical machines and systems, ICEMS 2017, pp 1-6

9. Belkhayat D, Roger D, Brudny JF (1997) Active reduction of magnetic noise in asynchronous machine controlled by stator current harmonics. In: 8th international conference on electrical machines and drives no. 444, pp 400-405

10. Cassoret B, Corton R, Roger D, Brudny JF (2003) Magnetic noise reduction of induction machines. IEEE Trans Power Electron 18(2):570-579

11. Franck D, Van Der Giet M, Hameyer K (2011) Active reduction of audible noise exciting radial force-density waves in induction motors. In: 2011 IEEE international electric machines and drives conference. IEMDC 2011, pp 1213-1218

12. Kärkkäinen I, Arkkio A (2010) Harmonic torque suppression by manual voltage injection. In: 19th international conference on electrical machines ICEM 2010, pp 1-6

13. Hollstegge P, Wanke A, De Doncker RW (2019) Noise mitigation in dual three-phase internal permanent magnet machines by injection of current harmonics. J Eng 2019(17):4273-4277

14. Harries M, Hensgens M, De Doncker RW (2018) Noise reduction via harmonic current injection for concentrated-winding permanent magnet synchronous machines ICEMS 2018. In: 2018 21st international conference on electrical machines and systems, pp $1157-1162$

15. Perez JJ, Abrahamsson C, Lundin U (2017) Demonstration of active compensation of unbalanced magnetic pull in synchronous machines. Cigre Sci Eng 8(June 2017):98-107

16. Perez-Loya JJ, Abrahamsson CJD, Lundin U (2019) Electromagnetic losses in synchronous machines during active compensation of unbalanced magnetic pull. IEEE Trans Ind Electron 66(1):124131

17. Ueda Y (1997) Harmonic compensation using a synchronous machine with resonant field circuits. IEEE Trans Energy Conversion, vol 12, no 2

18. Toliyat HA (2001) Harmonic compensation using advanced electric machines. Ind Electron Soc 2001. IECON '01., vol 00, no C, pp 1388-1393

19. Abolhassani MT, Toliyat HA, Enjeti P (2001) An electromechanical active harmonic filter IEMDC 2001. In: IEEE international electric machines and drives conference, pp 349-355

20. Fallows D, Nuzzo S, Costabeber A, Galea M (2017) Power quality improvement by pre-computed modulated field current for synchronous generators. In: 2017 IEEE workshop on electrical machines design, control and diagnosis (WEMDCD), pp 127-131

21. Walker JH, Kerruish N (1958) Design of fractional-slot windings. Proc IEE Part A Power Eng 105(22):428-440

22. Wallin M, Ranlöf M, Lundin U (2010) Design and construction of a synchronous generator test setup. In: 19th international conference on electrical machines ICEM 2010, pp 1-5

23. Evestedt $F$ (2015) Wireless control and measurement system for a hydropower generator with brushless exciter M.Sc. Thesis. Uppsala University, Uppsala, Sweden

24. Walker JH, Kerruish N (1960) Open-circuit noise in synchronous machines. Proc IEE Part A Power Eng 107(36):505-512

Publisher's Note Springer Nature remains neutral with regard to jurisdictional claims in published maps and institutional affiliations. 